\title{
Are Patients with Limb and Head Tremor a Clinically Distinct Subtype of Essential Tremor?
}

\author{
Abhishek Lenka, Ketaki Swapnil Bhalsing, Ketan Ramakant Jhunjhunwala, \\ Vijay Chandran, Pramod Kumar Pal
}

\begin{abstract}
Background: Essential tremor (ET) is the most common tremor disorder in adults. In addition to upper limbs, the tremor in ET may also involve head, jaw, voice, tongue, and trunk. Though head tremor (HT) is commonly present in patients with ET, large comparative studies of ET patients with HT (HT+) and without HT (HT-) are few. Methods: To determine whether ET with HT is a distinct clinical subtype by comparing ET patients with and without HT, a chart review of 234 consecutive patients with ET attending the neurology clinics of the National Institute of Mental Health and Neurosciences, India, was done. A movement disorder specialist confirmed the diagnosis of ET in all patients using the National Institutes of Health collaborative genetic criteria. Results: HT was present in $44.4 \%$ of the patients. Comparison between HT+ and HT- showed that the HT+ group patients: (1) were older, (2) had later onset of tremor, (3) had unimodal distribution of age at onset with a single peak in the fifth decade, (4) had more frequent voice tremor, and (5) were more likely to have mild cervical dystonia. HT was part of presenting symptoms in nearly two thirds of the ET patients and in the rest it was detected during clinical examination. Conclusions: Several demographic and clinical variables suggest that ET patients with HT have a distinct clinical phenotype.
\end{abstract}

RÉSUMÉ: Le tremblement des membres et de la tête constitue-t-il un sous-type de tremblement essentiel? Contexte: Le tremblement essentiel (TE) est le type de tremblement le plus fréquent chez les adultes. En plus des membres supérieurs, le tremblement essentiel peut également toucher la tête, la mâchoire, la voix, la langue et le tronc. Bien que le tremblement de la tête (TT) soit présent en général chez les patients atteints de TE, il y a peu de grandes études comparatives portant sur des patients atteints de TE avec TT (TT +) et sans TT (TT-). Méthode: Nous avons effectué une revue des dossiers de 234 patients consécutifs atteints de TE suivis à la clinique de neurologie du National Institute of Mental Health and Neurosciences en Inde afin de déterminer si le TE avec TT est un sous-type clinique distinct en comparant les patients atteints de TE avec et sans TT. Résultats: Le TT était présent chez $44,4 \%$ des patients. La comparaison entre le groupe TT + et le groupe TT- a montré que les patients du groupe TT + étaient plus âgés, que le début du tremblement était tardif, que la distribution de leur âge de début était unimodale avec un seul pic dans la cinquième décennie, que le tremblement de la voix était plus fréquent et qu'ils étaient plus susceptibles d'avoir une légère dystonie cervicale. Le TT faisait partie des symptômes initiaux chez presque les deux tiers des patients atteints de TE et chez les autres, il avait été détecté au cours de l'examen clinique. Conclusions: Plusieurs variables démographiques et cliniques suggèrent que les patients atteints de TE qui présentent un TT ont un phénotype clinique distinct.

Keywords: Cervical dystonia, essential tremor, head tremor, voice tremor

doi:10.1017/cjn.2015.23

Can J Neurol Sci. 2015; 42: 181-186

Essential tremor (ET) is a chronic neurologic disorder and is the most common cause of tremor in adults. ${ }^{1}$ In the recent literature on ET, there has been an improved understanding of the motor features of the illness and an increasing appreciation of non-motor features. ${ }^{2}$ The identification of non-motor features such as mild cognitive impairment, depression, anxiety, sleep disturbances, hearing impairment, and possible olfactory dysfunction suggests that ET is not a monosymptomatic disorder. ${ }^{3,4}$ In terms of motor features, specific features for tremor of the limbs, impairment in tandem gait, and cerebellar type oculomotor abnormalities have been described. The phenotypic expression of these features varies between patients. Pathologically, the majority of patients with ET have Purkinje cell loss and an increase in Purkinje cell torpedoes in the cerebellum as compared with matched controls. ${ }^{5}$ Less frequently, atypical brainstem Lewy bodies have been found. ${ }^{5}$ These findings have not been corroborated by other investigators. ${ }^{6,7}$ The heterogeneity of clinical features and pathology raises the possibility that ET is not a single entity, but a family of diseases. ${ }^{2}$

The characteristic clinical feature of ET is a bilateral postural with or without kinetic tremor of the hands. ${ }^{8}$ Tremor may also

From the Department of Clinical Neurosciences (AL, KSB, KRJ); Department of Neurology (AL, KSB, KRJ, VC, PKP), National Institute of Mental Health \& Neurosciences, Hosur Road, Bangalore-560029, Karnataka, India.

Received October 22, 2014. Final Revisions Submitted January 20, 2015. Correspondence to: Pramod Kumar Pal, Professor, Department of Neurology, National Institute of Mental Health \& Neurosciences (NIMHANS), Hosur Road, Bangalore560029, Karnataka, India. Email: pal.pramod@ rediffmail.com 
involve other parts such as head, neck, jaw, voice, and tongue. ${ }^{8}$ Epidemiological studies have shown that patients with head tremor (HT) are more likely to be older and female. ${ }^{9}$ In addition, there is preliminary evidence from imaging studies to suggest that ET patients with and without HT (HT+ and HT-) differ. ${ }^{2} \mathrm{We}$ further explored the hypothesis that ET is a family of diseases by examining whether ET patients who were HT+ differed from HTpatients based on demographic and clinical variables.

\section{MeTHODS}

This study was conducted at the Department of Neurology, National Institute of Mental Health and Neurosciences, Bangalore, India. Over a period of six years (2009-2014), patients with ET were recruited from the neurology outpatient and movement disorders clinic. Written informed consent was obtained from all participants. They were enrolled in several clinical studies, which were approved by the Institute Ethics Committee. All patients were evaluated by a single movement disorders specialist (PKP). The diagnosis of ET was established using the National Institutes of Health collaborative genetic criteria. ${ }^{10,11}$ Demographic parameters such as gender, age, age at onset (AAO), presence of family history, and chronology of body part involvement were documented. Collateral histories from accompanying relatives were also obtained. For analysis, decade-wise grouping of patients was done based on AAO. HT was assessed in patients while seated comfortably and it was documented as either present or absent. HT, which was irregular and jerky in nature, was diagnosed as dystonic head tremor and excluded. Upper limb tremor was assessed with the hands at rest on the lap, with upper limbs extended at the elbow and outstretched in front of the patient, with upper limbs flexed at the elbow and held in front of the chest with fingers facing each other but not touching, and while performing the finger nose test. Lower limb tremor was examined with the patient seated in a chair, while lying down in bed, with lower limbs lifted off the bed with flexion at the hip, and while performing the knee heel test. Voice tremor in the patients with ET was assessed by sustained phonation and by careful observation while conversing with the examiner. Trunk tremor was assessed when the patients were comfortably seated and later when standing. Any rhythmic sidewise tremulousness of the trunk was considered as trunk tremor, which was documented as either present or absent. ${ }^{12}$ Subjects with dystonic posturing of the limbs were excluded. However, subjects with subtle abnormal posturing of the head were not excluded, and were labeled to have mild cervical dystonia $(C D)$ in addition to ET. In these subjects posturing of the head was not a presenting symptom and was found only on careful examination. Detailed neurological examination was also performed. Descriptive statistics were performed using SPSS, version 21

\section{Results}

Overall, 234 subjects were studied. Details of clinical and demographic variables in patients with ET are provided in Table 1 The mean age was $46.6 \pm 16.6$ years (range 16-86 years), mean AAO was $38.7 \pm 17.8$ years and mean duration of symptoms was $7.3 \pm 7.9$ years. Men $(n=158)$ outnumbered women $(n=76)$. Family history of tremor was present in $44.9 \%(\mathrm{n}=105)$. Upper limb tremor was observed in all (97.5\% bilateral, $2.5 \%$ unilateral), whereas $38.4 \%(n=90)$ patients had lower limb tremor $(98.7 \%$
Table 1: Clinical and demographic features of patients with essential tremor

\begin{tabular}{l|c}
\hline Number of patients & 234 \\
\hline Age $($ mean $\pm \mathrm{SD})$ & $46.6 \pm 16.6$ years \\
\hline Male:female & $158: 76$ \\
\hline Age at onset $($ mean $\pm \mathrm{SD})$ & $38.7 \pm 17.8$ years \\
\hline Duration of tremor $($ mean $\pm \mathrm{SD})$ & $7.3 \pm 7.9$ years \\
\hline Family history of tremor & $105(44.5 \%)$ \\
\hline Upper limb tremor & $234(100 \%)$ \\
\hline Lower limb tremor & $90(38.4 \%)$ \\
\hline Head tremor & $104(44.4 \%)$ \\
\hline Voice tremor & $114(48.7 \%)$ \\
\hline Tongue tremor & $15(6.4 \%)$ \\
\hline Truncal tremor & $2(0.8 \%)$ \\
\hline Cervical dystonia & $32(13.7 \%)$ \\
\hline
\end{tabular}

SD: standard deviation.

bilateral, $1.3 \%$ unilateral). Other sites observed to have tremor: voice in $48.7 \%(n=114)$, head in $44.4 \%(n=104)$, tongue in $6.4 \%(\mathrm{n}=15)$, and trunk in $0.9 \%(\mathrm{n}=2)$. Mild CD was observed in $13.7 \%(n=32)$. The overlap of clinical features in patients with ET is shown in Figure 1

In the HT+ subgroup $(n=104)$, HT was a presenting symptom (either noted by the patients themselves or a collateral historian before consultation) in $65.4 \%(n=68)$. Among the latter, $58.8 \%$ $(\mathrm{n}=40)$ had HT as the first manifestation of ET, which was later, followed by limb tremor. Hence, nearly one third $(34.6 \%, \mathrm{n}=36)$ of the patients in the HT+ group had asymptomatic head tremor that was observed during the clinical examination at the time of first consultation.

Details of decade-wise analysis of AAO are provided in Figure 2. Two peaks for AAO were observed, one in the second and the other in the fifth decade. On subgroup analysis, the HT+ group had only one peak in the fifth decade, in contrast to the HTgroup, which had two peaks like the overall group.

Comparison of the $\mathrm{HT}+$ and $\mathrm{HT}-$ groups are provided in Table 2. The mean age and AAO in the HT+ group was significantly higher than the HT- group. There was no significant difference between the mean duration of tremor in both groups. The ratio of men to women in the HT+ group was 1.2:1, whereas in the HT- group it was $3.5: 1$, suggesting a high proportion of women in the HT+ group than the HT- group $(\mathrm{p}<0.01)$. In patients with HT as the initial symptom, women outnumbered men (ratio, 2.3:1). When grouped, based on the decade of onset, women outnumbered men in the fifth and sixth decades in the HT+ group, whereas men outnumbered women in rest of the decades. Performing the same analysis on patients with HT as the initial symptom, women outnumbered men in all decades. Details of the decade-wise gender distribution of age at tremor onset are given in Supplementary Table 1.

Voice tremor $(\mathrm{VT})(75 \%$ vs $27.7 \%, \mathrm{p}<0.01)$ and mild CD ( $28.8 \%$ vs $1.5 \%, \mathrm{p}<0.01)$ were significantly more common in HT + patients. The HT+ and HT- groups did not differ from each other significantly on the basis of other clinical features or family history. AAO was earlier in patients with mild CD compared with 


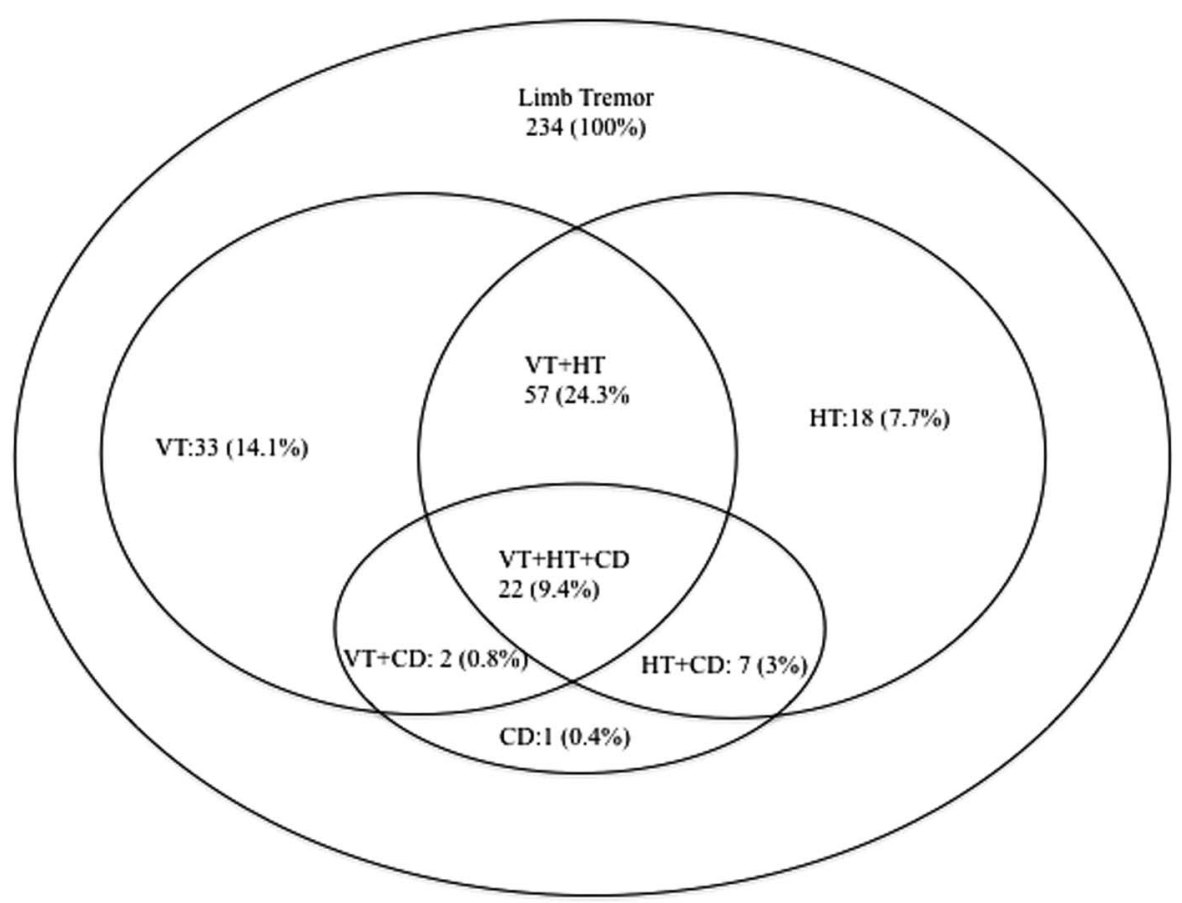

Figure 1: Venn diagram showing the extent of overlap of head tremor (HT), voice tremor (VT), and mild cervical dystonia $(C D)$ in patients with essential tremor (ET).

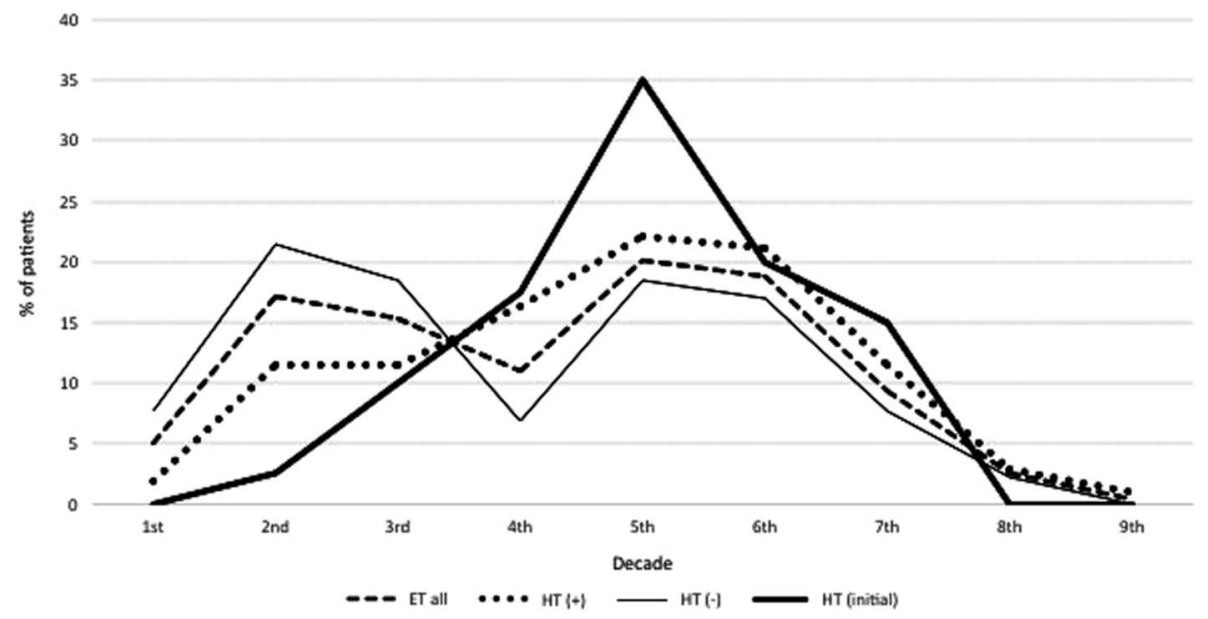

Figure 2: Distribution of patients according to the decade of tremor onset. ET: essential tremor, HT+: essential tremor patients with head tremor; HT-: ET patients without head tremor; HT (initial): ET patients with initial manifestation of head tremor.

those without $(41.7 \pm 3.6$ vs $42.5 \pm 3.1$ years, $\mathrm{p}=0.02)$. In the HT+ subgroup, the percentage of patients in which the head was the first affected body part was higher in those with $\mathrm{CD}$ compared with those without $\mathrm{CD}(50 \%$ vs $37 \%$, $\mathrm{p}=0.03)$.

\section{Comparison Between HT+ and HT- After Excluding Patients with Mild CD}

The aim of this analysis was to explore whether the differences discussed previously between the HT+ and HT- groups were influenced by the presence of $\mathrm{CD}$. The parameters, which were significantly different between the HT+ and HT- groups noted previously, remained significant even after excluding the patients with mild $\mathrm{CD}$ from the analysis (Table 2). The only change observed was a change in the peak decade of tremor onset in patients with HT to the sixth decade from the previously observed peak at fifth decade.

\section{Discussion}

In comparison to previously published studies, our patients were younger and had earlier tremor AAO (mean age in years, 
Table 2: Comparison of ET patients with and without HT

\begin{tabular}{|c|c|c|c|c|c|c|}
\hline & \multicolumn{2}{|c|}{ Including patients with mild CD } & \multirow[b]{2}{*}{$\mathbf{p}$} & \multicolumn{2}{|c|}{ Excluding patients with mild CD } & \multirow[b]{2}{*}{$\mathbf{p}$} \\
\hline & HT $+(n=104)$ & HT $-(n=130)$ & & HT $+(n=74)$ & HT- (128) & \\
\hline Age & $49.2 \pm 14.7$ & $44.5 \pm 17.7$ & 0.03 & $49.7 \pm 15.6$ & $44.5 \pm 17.8$ & 0.03 \\
\hline Male:female & $57: 47$ & $101: 29$ & $<0.01$ & $45: 29$ & $100: 28$ & 0.01 \\
\hline Age at onset & $42.3 \pm 16.4$ & $35.9 \pm 18.5$ & $<0.01$ & $42.5 \pm 17.5$ & $35.9 \pm 18.5$ & 0.01 \\
\hline Duration of tremor & $6.8 \pm 7.2$ & $7.7 \pm 8.4$ & NS & $7.1 \pm 7.9$ & $7.6 \pm 8.4$ & NS \\
\hline Family history of tremor & $47.1 \%(49)$ & $43.1 \%(56)$ & NS & $43.2 \%$ & $43.7 \%(56)$ & NS \\
\hline Upper limb tremor & $100 \%(104)$ & $100 \%(130)$ & NS & $100 \%(74)$ & $100 \%(128)$ & NS \\
\hline Lower limb tremor & $41.3 \%(43)$ & $36.2 \%(47)$ & NS & $37.8 \%(28)$ & $36.7 \%(47)$ & NS \\
\hline Voice tremor & $75 \%(78)$ & $26.7 \%(36)$ & $<0.01$ & $75.7 \%(56)$ & $25.7 \%(36)$ & $<0.01$ \\
\hline Tongue tremor & $9.6 \%(10)$ & $3.8 \%(5)$ & NS & $9.4 \%(7)$ & $3.9 \%(5)$ & NS \\
\hline Truncal tremor & $0.9 \%(1)$ & $0.7 \%(1)$ & NS & $1.3 \%(1)$ & $0.8 \%(1)$ & NS \\
\hline Cervical dystonia & $28.8 \%(30)$ & $1.5 \%(2)$ & $<0.01$ & & & \\
\hline
\end{tabular}

ET: essential tremor; HT: head tremor; HT+: ET patients with head tremor; HT-: ET patients without head tremor; CD: cervical dystonia; NS: not significant.

Age, age at onset, and duration of tremor are presented in years (mean \pm standard deviation). Number of subjects is in parentheses.

mean AAO in years of previous studies; Whaley et $\mathrm{al}^{13}: 71 \pm 13$, $52 \pm 22$; Louis et al $^{14}: 68.9 \pm 14.7,47.1 \pm 22.1$; Louis et $\mathrm{al}^{15}$ : $66.4 \pm 16.1,45.1 \pm 21.7)$. AAO is subject to recall bias that can be minimized by obtaining collateral history from family members, ${ }^{14}$ which we undertook in our patients. Prior studies have reported a bimodal distribution for age of onset in ET with peaks in the second and sixth decades ${ }^{15,16}$ and inconsistent results regarding gender distribution. ${ }^{13,17}$ In our study, we found a bimodal distribution of AAO with peaks in the second and fifth decades, and men outnumbered women. The reason for a skewed gender distribution in our study is not clear, but may partly be due to a referral bias secondary to sociocultural factors: women in our country have less access to medical facilities.

HT has been reported in $35 \%$ to $50 \%$ of patients with ET in previous clinic and community based studies. ${ }^{13,18,19}$ We found a similar frequency of HT, despite having a slightly different cohort in terms of age and AAO. In one study, the frequency of HT varied based on the population being studied, being lower in a community setting and higher in a tertiary referral centre $(12.3 \%$ vs $37.2 \%) .{ }^{20}$ This may be attributed to difficulty concealing head tremor from friends and relatives, which would encourage consultation with a specialist. Interestingly, quite often patients with ET are unaware of their HT, even if it was moderate or severe in intensity. ${ }^{20}$ Lack of self-awareness in HT was also seen in our study: $34.6 \%$ of patients with HT did not report it on presentation. This observation is of relevance: studies in which HT is identified based purely on self-reporting are likely to be inaccurate-an important example of this would be genetic linkage studies that are dependent on whether individuals participating are affected or not.

Patients with HT were older and had later onset of tremor as compared with patients without HT. Moreover, patients with HT had a unimodal distribution for AAO with a peak observed in the fifth decade and an almost even gender distribution. No significant differences were observed in duration of tremor between the two groups. These findings are similar to observations published by another group, ${ }^{9}$ but they did not report on the distribution of AAO and found that patients with HT were more likely to be women. The authors postulated that development of HT in ET is driven by biological factors intrinsic to the patient, such as age and gender rather than disease-related factors, such as duration of illness. ${ }^{9}$ Other studies also suggest that HT is more common in women. ${ }^{18,19}$ Although we found HT to be almost equally present in both genders, this was against the trend for the overall ET group wherein men markedly outnumbered women. Moreover, in patients with $\mathrm{HT}$ and AAO in the fifth or sixth decade, women outnumbered men, and in all decades, women were more likely than men to have $\mathrm{HT}$ as the first symptom. These observations suggest an underlying link between HT and female gender, especially in those patients with $\mathrm{HT}$ as the first symptom, and those with onset of symptoms in the fifth and sixth decades.

Previous studies in ET have suggested that HT usually appears after limb tremor. ${ }^{18,19}$ In our study, $38.5 \%$ of patients had HT as the initial manifestation. Hence, although HT usually follows limb tremor in ET, the reverse does occur. On cross-sectional examination, subjects whose illness begins with HT may present with isolated HT. According to the consensus statement of the Movement Disorder Society, these patients can be classified as having ET, provided they do not have abnormal posturing, which is an exclusion criteria. ${ }^{21}$ A questionnaire study by $\mathrm{Pal}$ et al has shown that HT may precede CD. ${ }^{22}$ Can patients with isolated HT and no abnormal posturing go on to develop CD? This is a question that, to our knowledge, remains unanswered. Studies have shown that patients with limb tremor that otherwise looks like classical ET can go on to develop $\mathrm{CD} .^{23}$ Some authors suggest that limb tremor in $\mathrm{CD}$ is more likely to be irregular, asymmetric, and associated with myoclonus. Electrophysiology may help in further characterization and can help differentiate limb tremor of ET and CD. ${ }^{24,25}$ In our study, mild CD was observed in $13.7 \%$ of patients with ET and was seen more often in patients with HT. Abnormal posturing is an exclusion criterion for the diagnosis of ET according to the consensus statement of the Movement Disorder Society. ${ }^{21}$ Some authors have suggested that the clinical significance of subtle head or limb posturing in ET is unclear. The exclusion of patients with these findings from research studies may result in too narrow a 
definition of ET, thereby limiting our ability to identify epidemiological associations. We included patients with mild CD to explore the relationship between HT and mild CD in patients with tremor that otherwise appears consistent with ET. By doing so, we found an association between HT and mild CD; moreover, patients whose onset was with HT were more likely to have mild CD. As the presence of mild CD along with HT may be confused with dystonic HT, we did a comparative analysis of ET patients with and without HT after excluding all the patients with mild CD. However, the findings were not different from the earlier analysis which included patients with mild CD. Because the results remained unchanged even after exclusion of a substantial number patients with mild CD ( $n=32,13.7 \%$ of the total cohort), the difference between the HT+ and HT- groups observed earlier were unlikely because of the presence of HT secondary to CD.

The prevalence of VT in ET has been reported to be $10 \%$ to $62 \% .{ }^{26}$ VT was present in $48.7 \%$ of patients in our study, and was more commonly seen in patients with HT. This association could result from head oscillations influencing the vocal air stream and thereby inducing a quiver in the voice ${ }^{27}$ or by shared diseaserelated pathophysiology as outlined in the following section.

The cerebellum has been postulated to be the site of abnormality in ET. ${ }^{2}$ The somatotopic organization of the cerebellum is such that head and neck regions are represented medially in the vermis; limbs are represented in the cerebellar hemispheres. ${ }^{18}$ The site of initial pathology and its spread could determine the clinical presentation. Based on this hypothesis, patients with cranial tremors (HT and VT) are likely to have pathological changes in the vermis; this has been shown in a study that found a correlation between the number of vermian Purkinje cell torpedoes and cranial tremors. ${ }^{28}$ In addition, a magnetic resonance imaging study using voxel-based morphometry has shown vermian atrophy in $\mathrm{HT}+$ patients with ET. ${ }^{29}$ In view of the association with older age, normal aging may itself play a role in the manifestation of HT. There is evidence of cerebellar volume loss with normal aging; this loss can preferentially affect certain regions such as the vermis. $^{30,31}$ Gender differences in regional cerebellar volumes have also been described, although these observations have not been consistent. ${ }^{32}$ The increased frequency of HT in patients who are older and female may be related to the compounding effect of ET pathology on these underlying differences in the cerebellum. Gender differences could also be related to the effect of sex hormones in disease pathogenesis or its clinical presentation. ${ }^{19}$

As discussed, HT+ patients have several distinct clinical and demographic features compared with HT- patients, such as older age, later AAO which has a unimodal distribution, increased association with VT and mild CD, and-although not clearly demonstrated in our study - an association with female gender. In view of these differences, it does appear that ET patients with HT are a distinct clinical phenotype. Being a distinct phenotype, it is currently a matter of speculation whether HT+ patients should be considered a subtype of ET or a separate disease entity. HT in ET and $\mathrm{CD}$ have similarities: association with female gender, ${ }^{27}$ similar clinical presentation, and slow progression in severity of limb tremor. ${ }^{25,33}$ This reemphasizes the concern that some patients diagnosed with ET and $\mathrm{HT}+$ have $\mathrm{CD}$ as the underlying etiology. This may be especially true for those with HT at onset.

Our study has limitations: because it was a hospital-based study, which evaluated AAO and spread of tremor based on patient history, there is a referral as well as a recall bias in our data.
Electrophysiologic assessments were not performed; these could have helped to accurately differentiate ET with $\mathrm{HT}+$ from a dystonic HT in patients with mild CD. The strengths of our study are the large sample size and careful clinical examination of all patients performed by a single movement disorders specialist. Further studies on a larger cohort of ET patients with and without HT along with electrophysiology, voice recording, and vocal cord assessments are warranted to give more insight into our understanding of HT in ET.

\section{Disclosures}

None of the authors have any financial disclosures to make or have any conflicts of interest.

\section{SUPPLEMENTARY MATERIAL}

To view supplementary material for this article, please visit http://dx.doi.org/10.1017/cjn.2015.23

\section{REFERENCES}

1. Louis ED, Ferreira JJ. How common is the most common adult movement disorder? Update on the worldwide prevalence of essential tremor. Mov Disord. 2010;25:534-41.

2. Louis ED. Essential tremor: from bedside to bench and back to bedside. Curr Opin Neurol. 2014;27:461-7.

3. Jhunjhunwala K, Pal PK. The non-motor features of essential tremor: a primary disease feature or just a secondary phenomenon? Tremor Other Hyperkinet Mov. 2014;4.

4. Chandran V, Pal PK. Essential tremor: beyond the motor features. Park Relat Disord. 2012;18:407-13.

5. Louis ED, Faust PL, Vonsattel JP, et al. Neuropathological changes in essential tremor: 33 cases compared with 21 controls. Brain. 2007; 130:3297-307.

6. Rajput AH, Robinson CA, Rajput ML, Rajput A. Cerebellar Purkinje cell loss is not pathognomonic of essential tremor. Parkinsonism Relat Disord. 2011;17:16-21.

7. Symanski C, Shill HA, Dugger B, et al. Essential tremor is not associated with cerebellar Purkinje cell loss. Mov Disord. 2014;29:496-500.

8. Elble RJ. What is essential tremor? Curr Neurol Neurosci Rep. 2013;13:353.

9. Louis E. D. When do essential tremor patients develop head tremor? Influences of age and duration and evidence of a biological clock. Neuroepidemiology. 2013;41:110-5.

10. Carranza MA, Snyder MR, Elble RJ, Boutzoukas AE, Zesiewicz TA. Methodological issues in clinical drug development for essential tremor. Tremor Other Hyperkinet Mov (N Y). 2012;2:1-4.

11. Chouinard S, Louis ED, Fahn S. Agreement among movement disorder specialists on the clinical diagnosis of essential tremor. Mov Disord. 1997;12:973-6.

12. Rivest J, Marsden CD. Trunk and head tremor as isolated manifestations of dystonia. Mov Disord. 1990;5:60-5.

13. Whaley NR, Putzke JD, Baba Y, Wszolek ZK, Uitti RJ. Essential tremor: phenotypic expression in a clinical cohort. Parkinsonism Relat Disord. 2007;13:333-9.

14. Louis ED, Ottman R. Study of possible factors associated with age of onset in essential tremor. Mov Disord. 2006;21:1980-6.

15. Louis ED, Dogu O. Does age of onset in essential tremor have a bimodal distribution? Data from a tertiary referral setting and a population-based study. Neuroepidemiology. 2007;29:208-12.

16. Lou JS, Jankovic J. Essential tremor: clinical correlates in 350 patients. Neurology. 1991;41:23-8.

17. Benito-León J, Bermejo-Pareja F, Morales JM, Vega S, Molina JA. Prevalence of essential tremor in three elderly populations of central Spain. Mov Disord. 2003;18:389-94.

18. Louis ED, Ford B, Frucht S. Factors associated with increased risk of head tremor in essential tremor: a community-based study in northern Manhattan. Mov Disord. 2003;18:432-6.

19. Hardesty DE, Maraganore DM, Matsumoto JY, Louis ED. Increased risk of head tremor in women with essential tremor: longitudinal 
data from the Rochester Epidemiology Project. Mov Disord. 2004;19:529-33.

20. Louis ED, Pellegrino KM, Rios E. Unawareness of head tremor in essential tremor: a study of three samples of essential tremor patients. Mov Disord. 2008;23:2423-4.

21. Deuschl G, Bain P, Brin M. Consensus statement of the Movement Disorder Society on Tremor. Ad Hoc Scientific Committee. Mov Disord. 1998;13:2-23.

22. Pal PK, Samii A, Schulzer M, Mak E, Tsui JK. Head tremor in cervical dystonia. Can J Neurol Sci. 2000;27:137-42.

23. Schiebler S, Schmidt A, Zittel S, et al. Arm tremor in cervical dystonia-is it a manifestation of dystonia or essential tremor? Mov Disord. 2011;26:1789-92.

24. Shaikh AG, Jinnah HA, Tripp RM, et al. Irregularity distinguishes limb tremor in cervical dystonia from essential tremor. J Neurol Neurosurg Psychiatry. 2008;79:187-9.

25. Münchau A, Schrag A, Rothwell C, et al. Arm tremor in cervical dystonia differs from essential tremor and can be classified by onset age and spread of symptoms. Brain. 2001;124:1765-76.

26. Sulica L, Louis ED. Clinical characteristics of essential voice tremor: a study of 34 cases. Laryngoscope. 2010;120:516-28.
27. Duane DD. Sex and tremor location: similarities between essential tremor and cervical dystonia. Mov Disord. 2005;20: 119-120.

28. Louis ED, Faust PL, Ma KJ, Yu M, Cortes E, Vonsatell JP. Torpedoes in the cerebellar vermis in essential tremor cases vs. controls. Cerebellum. 2011;10:812-9.

29. Quattrone A, Cerasa A, Messina D, et al. Essential head tremor is associated with cerebellar vermis atrophy: a volumetric and voxel-based morphometry MR imaging study. AJNR. 2008;29: 1692-7.

30. Bernard JA, Seidler RD. Relationships between regional cerebellar volume and sensorimotor and cognitive function in young and older adults. Cerebellum. 2013;12:721-37.

31. Torvik A, Torp S, Lindboe CF. Atrophy of the cerebellar vermis in ageing. A morphometric and histologic study. J Neurol Sci. 1986;76:283-94.

32. Fan L, Tang Y, Sun B, et al. Sexual dimorphism and asymmetry in human cerebellum: an MRI-based morphometric study. Brain Res. 2010;1353:60-73.

33. Louis ED, Ford B, Barnes LF. Clinical subtypes of essential tremor. Arch Neurol. 2000;57:1194-8. 